\title{
Theoretical Analysis and Numerical Simulation of the Graben Fault Instability Mechanism
}

\author{
Qihua Ma, ${ }^{1}$ Shiwei Niu (D), ${ }^{1,2}$ Huaguo Wang $\mathbb{D}^{1},{ }^{1}$ Weixiang Ma, ${ }^{1}$ Lihui Chi, ${ }^{1}$ and Xiao Wan ${ }^{3}$ \\ ${ }^{1}$ College of Energy and Mining Engineering, Shandong University of Science and Technology, Qingdao 266590, China \\ ${ }^{2}$ National Demonstration Center for Experimental Mining Engineering Education, \\ Shandong University of Science and Technology, Qingdao 266590, China \\ ${ }^{3}$ Shandong Xinjulong Energy Limited Company, Shandong Energy Xinwen Mining Group Co.,Ltd., Heze 274918, China \\ Correspondence should be addressed to Shiwei Niu; nshiwei1123@163.com
}

Received 26 May 2021; Revised 8 September 2021; Accepted 24 September 2021; Published 6 October 2021

Academic Editor: FuRen Ming

Copyright (C) 2021 Qihua Ma et al. This is an open access article distributed under the Creative Commons Attribution License, which permits unrestricted use, distribution, and reproduction in any medium, provided the original work is properly cited.

\begin{abstract}
The rock burst caused by geological structures is abrupt and destructive, and the special structure of a graben fault decides the uniqueness of mine ground pressure in the mining process. By simplifying the graben fault structure, the evolution law of roof stress during the recovery process was studied based on the theory of the elastic shear beam. The change laws of stress field and displacement nearby the fault during the advancement process of the working face were explored through a numerical simulation, and the instability mechanism and laws of rock strata nearby this graben fault were revealed. This study will be of great significance for preventing and controlling the rock burst in the graben fault.
\end{abstract}

\section{Introduction}

Fault rock burst accidents often occur when the mining activities are close to the fault. The fault suddenly ruptures and dislocates under the influence of mining activities, which has the characteristics of releasing more energy, large magnitude, deep focal point, and large damage intensity [1-3]. With the gradual increase of mining depth, the mine pressure becomes more and more serious [4]. On February 22,2020 , a rock burst-induced accident took place in the upper entry of a $2305 \mathrm{~S}$ fully mechanised caving face at the south wing of $-810 \mathrm{~m}$ horizontal No. 2 mining area of Shandong New Dragon Energy Co., Ltd., in China, leading to four deaths and a direct economic loss of RMB 18,530,000. As one of the coal or rock dynamic disasters, rock bursts-a special strata pressure behaviour-are a dynamic phenomenon generated by the release of deformation energy in mine roadways and coal and rock mass around stopes, which is featured by sudden, abrupt, and violent destruction [5-7].

With the increase in mining depth and intensity of coal mine resources, dynamic disasters including mining-induced rock bursts are increasingly aggravated, thus seriously threatening coal mining safety. Statistical analysis shows that all types of mines have reported the occurrence of rock bursts, as well as in various coal seams-from thin to ultrathick coal seams and horizontal to steep dip angles-and in conglomerate, sandstone, limestone, and kerogen shale roofs $[5,8,9]$. Faults, which are geological structures extensively distributed in the earth's crust, are usually developed in groups in various combinations. Most of the eastern coal mines in Northern China are tectonically characterised by faults, which are developed in groups and usually appear in forms like graben $[10,11]$.

\section{Project Overview}

In this accident, there were six faults within the 2305 S fully mechanised caving face in the New Dragon Mine, two of which generated a great impact on the mining, namely, FD8 and FD11. The spacing between FD6 and FD8 faults is $278 \mathrm{~m}$ and presents identical strikes, forming a wedge-shaped graben structure. Another four small faults had a minor influence on the mining. The on-site graben structure is shown in Figure 1, 


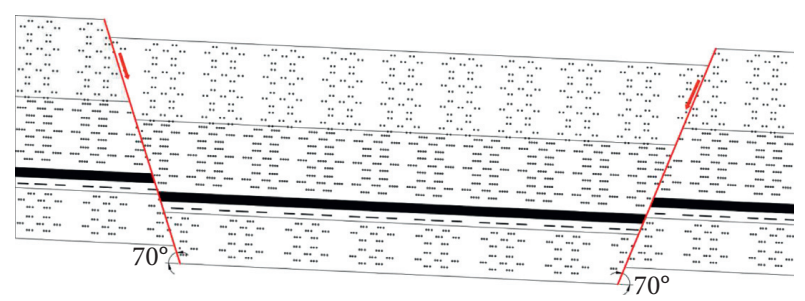

Figure 1: Description of the graben structure.

from top to down are medium sandstone, fine sandstone, coal, mudstone, and medium-fine sandstone $[12,13]$.

The graben structure is composed of over two normal faults with opposite tendencies, with the upper and lower footwalls of the surrounding rock constituting a deformation system. Before mining, the medium in the fault zone is under an equilibrium state with rock masses at upper and lower footwalls. Following coal seam mining (or roadway excavation), additional stress will be formed. Under the joint action of original shear stress and additional stress, the rocks in the fault zone deform and accumulate energy gradually. When the coal mining face (or excavation roadway) is distant from the fault, the additional shear stress is small so that the rock stress in the fault zone is below the peak strength, and the rocks maintain a steady state. As the coal mining face (or excavation roadway) approaches the fault, the distance from the working face to the fault is reduced, and the additional stress is gradually enlarged. When the sum of the additional shear stress and original shear stress is greater than the peak strength, the rocks in the fault zone are under an unsteady state, while the surrounding rocks at the upper and lower footwalls of the fault are still stable. As such, the whole deformation system nearby the fault consists of an unsteady state in the fault zone and a stable state in surrounding rocks at the upper and lower footwalls of the fault. As the roadway is excavated to one critical position, the whole deformation system becomes unsteady, and the accumulated deformation energy is suddenly released, which leads to instability and rock burst $[11,14]$. The nearby rocks have obvious brittle failure characteristics [15]. In addition, when the fault meets aquifers, water plays a positive role in rock damage evolution, which can decrease the energy threshold of the rock burst [16].

To sum up, the activation of graben fault groups is inseparable from the occurrence of rock burst accidents. Based on the theory of elastic shear beams [17-19], the evolution laws of stress fields and displacements nearby the fault during the advancement process of the working face are explored through a numerical simulation of a simplified graben fault structure. Next, the instability mechanism and laws of rock strata nearby the graben fault are revealed, which will be of great significance for preventing and controlling a rock burst in graben faults. At the same time, it can provide some references for backmining near graben faults $[20,21]$.

\section{Instability Mechanism Study of the Graben Fault Based on the Elastic Shear Beam}

During the mining of the working face, the stress fields in coal seam and overlying strata will be changed. Given this, in order to theoretically analyse the evolution of stress fields through reasonable simplification, the roof was simplified into an elastic shear beam in this study. So, it is assumed that the roof only produces shear deformation, and this paper ignores the friction between the roof and the coal, as shown in Figure 2. The positions on the roof at which the maximum equivalent shear force appeared under both elastic and plastic support conditions were determined, and the roof element at the graven fault was analysed.

3.1. Basic Equation of the Ordinary Roof Element. Roof: it is simplified into an elastic shear beam. Assume that the roof thickness is $D$, and it undertakes the overburden pressure and dead weight uniformly distributed along the direction of the working face. The two can be simplified into a load $q(x)$, and the acting force of the lower coal seam on the roof can be simplified into the load $p(x) . \gamma$ is the shear strain, $\tau$ is the shear stress, $w$ is the deflection (i.e., the roof deflection), and $G$ is the shear modulus of elasticity, as shown in Figure 3(a).

An element body microsection of length $d x$ was taken as the study object and considered from the aspects of statics, geometrical relationship, and physical conditions.

(1) Equilibrium condition:

$$
p(x) \mathrm{d} x-q(x) \mathrm{d} x=D \mathrm{~d} \tau .
$$

(2) Geometrical relationship:

$$
\mathrm{d} w=\gamma \mathrm{d} x .
$$

(3) Physical equation:

$$
\tau=G \gamma
$$

The equations of the equivalent shear force and deflection of the ordinary roof can be obtained as follows:

$$
\begin{aligned}
\mathrm{d} Q & =D \mathrm{~d} \tau, \\
\frac{\mathrm{d}^{2} w}{\mathrm{~d} x^{2}} & =\frac{p(x)-q(x)}{G D} .
\end{aligned}
$$

\subsection{Basic Equation of the Roof Element in the Graben Fault.} Assume that the oblique section $A B$ has a length of $\mathrm{d} s$. An element length is taken along the width direction, and the acting force of the lower coal seam can be simplified into the load $p(x)$. This element body was taken as the study object to analyse the stress on the roof of the graben structure at an arbitrary dip angle of $\theta$, as shown in Figure 3(b).

According to the basic theory of the plane problem, 


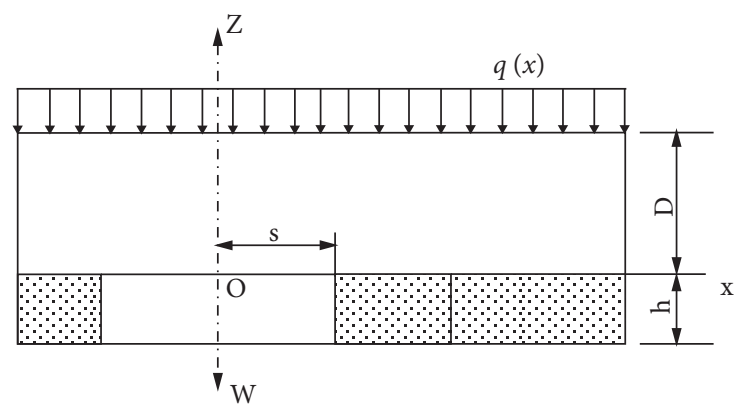

FIGURE 2: Shear beam calculation model.

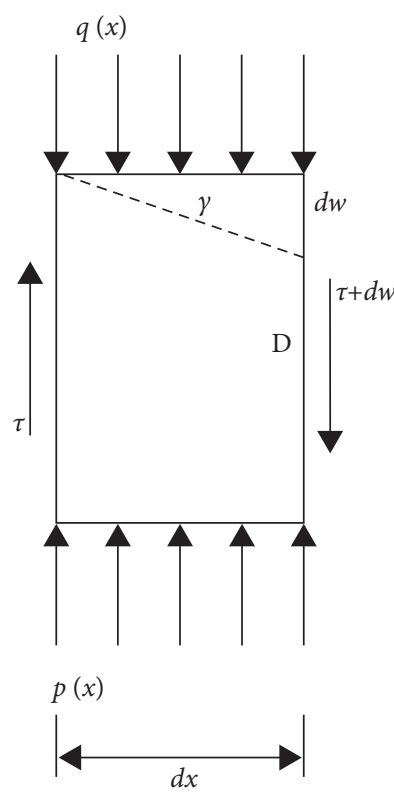

(a)

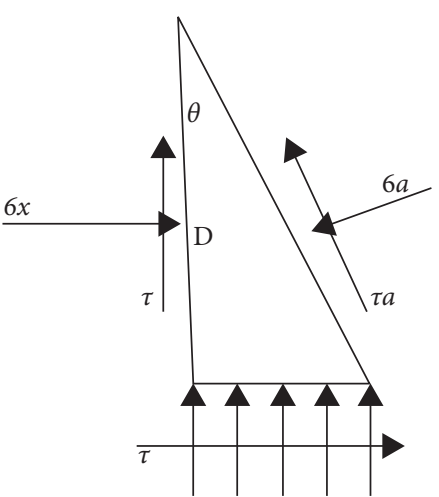

$q(x)$

Figure 3: Stress state of the common roof element and graben roof element.

$\sigma_{N}=\sigma_{x} \cos ^{2} \theta-\tau_{x y} \sin 2 \theta-p(x) \sin ^{2} \theta+\sigma_{y} \sin ^{2} \theta$

$$
\tau_{N}=\tau_{x y}\left(\cos ^{2} \theta-\sin ^{2} \theta\right)+\frac{1}{2}\left[p(x)+\sigma_{x}-\sigma_{y}\right] \sin 2 \theta
$$

3.3. Solution to the Basic Equation. It is assumed that the roof and coal seam are homogenous and isotropic. The compressive deformation $w$ is generated under the influence of the overburden pressure and dead weight $p(x)$. Before $p(x)$ reaches the peak strength, $p(x)=k w$, where $k$ is the average vertical stiffness of the roof and coal seam. After reaching the peak strength $p_{m}, p(x)$ will present a linear reduction with an increase in the deformation $w$, namely, $p(x)-p_{m}=-k_{r}\left(w-w_{m}\right)$, where $w_{m}=p_{m} / k$ and $k_{r}$ is the average softening stiffness of the roof and coal seam, respectively. When $w$ reaches $w_{s}$, the coal seam will be extruded and crushed, but the residual strength still exists. The residual strength of coal is about $0.4 p_{m}$ [22]. In other words, $p(x)$ and $w$ meet the following relational expression:

$$
P(x)= \begin{cases}k w, & 0 \leq w \leq w_{m}, \\ p_{m}\left(1+\frac{k_{r}}{k}\right)-k_{r} w, & w_{m} \leq w \leq w_{s}, \\ 0.4 p_{m}, & w \geq w_{s} .\end{cases}
$$

The solutions under all kinds of circumstances will be discussed.

In the following, $c_{i}, i=1,2, \ldots, 8$, are all integral constants, which can be solved by boundary conditions.

(1) The undersurface is a goaf without support, and under this condition, $p(x)=0$ and $q(x)=$ const.

For the roof element: 
The condition is substituted into equations (4) and (5) to obtain the following:

$$
\begin{aligned}
& Q_{1}=-q x+c_{1}, \\
& w_{1}=\frac{-(q / 2) x^{2}+c_{1} x+c_{2}}{G D} .
\end{aligned}
$$

For the graben fault-type roof element:

The following can be solved by substituting the above conditions into equations (6) and (7):

$$
\begin{aligned}
& \sigma_{N}=\sigma_{x} \cos ^{2} \theta-\tau_{x y} \sin 2 \theta+\sigma_{y} \sin ^{2} \theta, \\
& \tau_{N}=\tau_{x y}\left(\cos ^{2} \theta-\sin ^{2} \theta\right)+\frac{1}{2}\left(\sigma_{x}-\sigma_{y}\right) \sin 2 \theta .
\end{aligned}
$$

(2) The goaf on the undersurface is of a small span, and the elastic support can be considered. Under this condition, $p(x)=k w$ and $q(x)=$ const.

For the roof element:

The condition is substituted into equations (4) and (5) to solve

$$
\begin{aligned}
Q_{2} & =G D \sqrt{\frac{k}{G D}}\left[c_{3} e^{\sqrt{(k / G D)} x}-c_{4} e^{-\sqrt{(k / G D)} x}\right], \\
w_{2} & =c_{3} e^{\sqrt{(k / G D)} x}+c_{4} e^{-\sqrt{(k / G D)} x}+\frac{q}{k} .
\end{aligned}
$$

For the graben fault-type roof element:

If this roof element is close to the graben fault-type roof element, the compressive deformation $w$ is approximately identical. The condition is substituted into equations (6) and (7) to obtain

$$
\begin{aligned}
& \sigma_{N}=\sigma_{x} \cos ^{2} \theta-\tau_{x y} \sin 2 \theta+\sigma_{y} \sin ^{2} \theta-k w_{2} \sin ^{2} \theta, \\
& \tau_{N}=\tau_{x y}\left(\cos ^{2} \theta-\sin ^{2} \theta\right)+\frac{1}{2}\left(k w_{2}+\sigma_{x}-\sigma_{y}\right) \sin 2 \theta .
\end{aligned}
$$

(3) The span of the goaf on the undersurface is gradually enlarged, and the plastic support appears. Under this condition, $p(x)=p_{m}$ $\left(1+\left(k_{r} / k\right)\right)-k_{r} w$ and $q(x)=$ const.

For the roof element:

The following can be solved by substituting the above condition into equations (4) and (5):

$$
\begin{aligned}
& Q_{3}=G D \sqrt{\frac{k_{r}}{G D}}\left[c_{5} \cos \left(\sqrt{\frac{k_{r}}{G D}} x\right)-c_{6} \sin \left(\sqrt{\frac{k_{r}}{G D}} x\right)\right], \\
& w_{3}=c_{5} \sin \left(\sqrt{\frac{k_{r}}{G D}} x\right)+c_{6} \cos \left(\sqrt{\frac{k_{r}}{G D}} x\right)+\frac{p_{m}\left(1+\left(k_{r} / k\right)\right)-q}{k_{r}} .
\end{aligned}
$$

For the graben fault-type roof element:

If this roof element is close to the graben fault-type roof element, the compressive deformation $w$ is approximately identical. The condition is substituted into equations (6) and (7) to obtain

$$
\begin{aligned}
& \sigma_{N}=\sigma_{x} \cos ^{2} \theta-\tau_{x y} \sin 2 \theta+\sigma_{y} \sin ^{2} \theta-\left[p_{m}\left(1+\frac{k_{r}}{k}\right)-k_{r} w_{3}\right] \sin ^{2} \theta, \\
& \tau_{N}=\tau_{x y}\left(\cos ^{2} \theta-\sin ^{2} \theta\right)+\frac{1}{2}\left\{\left[p_{m}\left(1+\frac{k_{r}}{k}\right)-k_{r} w_{3}\right]+\sigma_{x}-\sigma_{y}\right\} \sin 2 \theta . \\
& Q_{4}=\left(0.4 p_{m}-q\right) x+c_{7}, \\
& \text { s a residual zone, and the coal } \\
& \text { amaged. Under this condition, } \\
& w_{4}=\frac{\left(0.2 p_{m}-(q / 2)\right) x^{2}+c_{7} x+c_{8}}{G D} .
\end{aligned}
$$

For the roof element:

The condition is substituted into equations (4) and (5) to obtain
For the graben fault-type roof element:

The following can be solved by substituting the condition into equations (6) and (7): 


$$
\begin{aligned}
& \sigma_{N}=\sigma_{x} \cos ^{2} \theta-\tau_{x y} \sin 2 \theta+\sigma_{y} \sin ^{2} \theta-0.4 p_{m} \sin ^{2} \theta, \\
& \tau_{N}=\tau_{x y}\left(\cos ^{2} \theta-\sin ^{2} \theta\right)+\frac{1}{2}\left(0.4 p_{m}+\sigma_{x}-\sigma_{y}\right) \sin 2 \theta .
\end{aligned}
$$

3.4. Stope Pressure Analysis and Early Warning. In general, the span of the goaf will experience an increasing trend during coal mining. The coal seam will then be transited from the elastic support into plastic support until it is damaged and the shear force borne by the roof changes [23]. The graben fault-type roof has extremely weak shear resistance due to its disadvantage in its natural structure, so the maximum shear force of the roof and shear force of the graben fault-type roof are mainly analysed below. The shear strength of the fault $\tau_{f}=\sigma_{N} \tan \varphi+c$, where $\phi$ is the angle of internal friction and $c$ is the cohesion.

3.4.1. Elastic Support State. Assume that the position with the maximum span of elastic support is $x=s_{1}$.

The initial values are as follows: $w(0)=0$ and $w\left(s_{1}\right)=w_{m}$.

The following can be solved:

$$
\left\{\begin{array}{c}
c_{3}=\frac{w_{m}+(q / k)\left(e^{-\sqrt{k / G D} s_{1}}-1\right)}{e^{\sqrt{k / G D} s_{1}}-e^{-\sqrt{k / G D} s_{1}}}, \\
c_{4}=-\frac{w_{m}+(q / k)\left(e^{-\sqrt{(k / G D)} s_{1}}-1\right)}{e^{\sqrt{k / G D} s_{1}}-e^{-\sqrt{k / G D} s_{1}}}-\frac{q}{k} .
\end{array}\right.
$$

From equation (11), the maximum shear force appears at the position of $x=s_{1}$, namely,

$$
Q_{\max }=G D \sqrt{\frac{k}{G D}}\left[c_{3} e^{\sqrt{k / G D} s_{1}}-c_{4} e^{-\sqrt{k / G D} s_{1}}\right] .
$$

For the graben fault-type roof element,

$$
\tau_{N}=\tau_{x y}\left(\cos ^{2} \theta-\sin ^{2} \theta\right)+\frac{1}{2}\left(k w_{2}+\sigma_{x}-\sigma_{y}\right) \sin 2 \theta .
$$

According to equation (12), the maximum deformation takes place at $x=s_{1}$ :

$$
w_{2}=c_{3} e^{\sqrt{k / G D} s_{1}}+c_{4} e^{-\sqrt{k / G D} s_{1}}+\frac{q}{k} .
$$

If the roof thickness is $D$, the oblique sectional length of the graben fault is $L=D / \cos \theta$.

The oblique sectional shear force of the graben fault is $Q=\int_{L} \tau_{N} \mathrm{~d} s$

3.4.2. Plastic Support State. At this time, $x>s_{1}$. When $x \geq s_{2}$, the coal seam suffers extrusion and crushing.

The following are initial values: $w(0)=0$ and $w\left(s_{2}\right)=w_{s}$.

On this basis, the following can be solved:

$$
\left\{\begin{array}{l}
c_{5}=\frac{w_{s}+\left(\left(p_{m}\left(1+\left(k_{r} / k\right)\right)-q\right) / k_{r}\right)\left[\cos \left(\sqrt{k_{r} / G D} s_{2}\right)-1\right]}{\sin \left(\sqrt{k_{r} / G D} s_{2}\right)}, \\
c_{6}=\frac{q-p_{m}\left(1+\left(k_{r} / k\right)\right)}{k_{r}} .
\end{array}\right.
$$

According to $\mathrm{d} Q / \mathrm{d} x=0$ in equation (14), the following can be obtained:

$$
x_{\mathrm{Qmax}}=\frac{\arctan \left(-\left(c_{6} / c_{5}\right)\right)}{\sqrt{k_{r} / G D}} .
$$

The maximum shear force can be acquired by substituting equation (25) into equation (14) as follows:

$$
Q_{3}=G D \sqrt{\frac{k_{r}}{G D}}\left[c_{5} \cos \left(\sqrt{\frac{k_{r}}{G D}} x_{Q \max }\right)-c_{6} \sin \left(\sqrt{\frac{k_{r}}{G D}} x_{Q \max }\right)\left(\sqrt{\frac{k_{r}}{G D}} x_{Q \max }\right)-c_{6} \sin \left(\sqrt{\frac{k_{r}}{G D}} x_{Q \max }\right)\right] .
$$

For the graben fault-type roof element,

$$
\tau_{N}=\tau_{x y}\left(\cos ^{2} \theta-\sin ^{2} \theta\right)+\frac{1}{2}\left\{\left[p_{m}\left(1+\frac{k_{r}}{k}\right)-k_{r} w_{3}\right]+\sigma_{x}-\sigma_{y}\right\} \sin 2 \theta
$$


Based on $\mathrm{d} w / \mathrm{d} x=0$ in equation (15), the following can be solved:

$$
\begin{aligned}
x_{w \max }= & \frac{\arctan \left(c_{5} / c_{6}\right)}{\sqrt{k_{r} / G D}}, \\
w_{3}= & {\left[\frac{q-p_{c}\left(1+\left(k_{r} / k\right)\right)}{k_{r}}\right] \cos \left(\sqrt{\frac{k_{r}}{G D}} x_{w \max }\right) } \\
& +\frac{p_{m}\left(1+\left(k_{r} / k\right)\right)-q}{k_{r}} .
\end{aligned}
$$

Similarly, the oblique sectional shear force of the graben fault is $Q=\int_{L} \tau_{N} \mathrm{~d} s$.

3.4.3. Damaged Support State. At the moment, the coal seam is extruded and crushed already, and $x>s_{2}$ is satisfied.

The following are initial value conditions: $w(0)=0$ and $w\left(s_{2}\right)=w_{s}$.

Thus, the following can be acquired:

$$
\left\{\begin{array}{l}
c_{7}=\frac{w_{s} G D-\left[\left(0.2 p_{m}-q / 2\right) s_{2}^{2}\right]}{s_{2}}, \\
c_{8}=0 .
\end{array}\right.
$$

By substituting equation (29) into equation (17), it can be shown that the maximum shear force of the roof continuously increases with the increase in the span $x$, which can be expressed as follows:

$$
Q_{\max }=\left(0.4 p_{m}-q\right) x+c_{7}
$$

For the graben fault-type roof element,

$$
\tau_{N}=\tau_{x y}\left(\cos ^{2} \theta-\sin ^{2} \theta\right)+\frac{1}{2}\left(0.4 p_{m}+\sigma_{x}-\sigma_{y}\right) \sin 2 \theta .
$$

The maximum shear force no longer changes with the $\operatorname{span} x$, being $Q=\int_{L} \tau_{N} \mathrm{~d} s$.

Finally, judging the graben fault instability, this paper compares the relationship between the shear stress $\tau_{N}$ of the graben roof element and the shear strength $\tau_{\mathrm{f}}$ of the fault under different conditions. When $\left|\tau_{N}\right|<\tau_{f}$, the fault is still and gradually accumulates energy. When $\left|\tau_{N}\right|>\tau_{f}$, the fault shows tangential dislocation, and the accumulated energy is released. At the same time, the graben fault becomes unstable, and rock burst occurs.

To sum up, with the gradual increase in the goaf span, the supporting effect of the coal seam on the roof transits from the elastic support state into the plastic support state and, finally, the damaged support state. Under the elastic support state, the shear force of the roof and that of the graben faulttype roof present a continuous growth trend with the increase in the goaf span, both reaching peak values at the position with the maximum span of the elastic support. Under the plastic support state, they reach the peak values at the goaf span positions of $x_{Q \max }$ and $x_{w \max }$, respectively.
Under the damaged support state, the shear force of the roof increases with the span again, whilst the graben fault-type roof remains unchanged. Through the above analysis of different states, the concrete positions at which the roof and graben fault-type roof bear the maximum shear force are obtained and reinforced at fixed points, which, in production practice, can not only guarantee coal mining safety but also minimise the support cost. Furthermore, this can provide a certain reference for the coal mining work on complex topography containing graben faults in the future.

\section{Numerical Simulation Study of Rock Burst- Induced Instability in the Graben Fault}

4.1. Establishment of a Numerical Calculation Model. The 2305S fully mechanised caving face at the south wing of $-810 \mathrm{~m}$ horizontal No. 2 mining area of Shandong New Dragon Energy Co., Ltd., was taken as an example, where the spacing between FD6 and FD8 faults is $278 \mathrm{~m}$ and for which show consistent strikes and form a wedge-shaped structure together. According to the practical mining condition, the $2304 \mathrm{~S}$ and $2305 \mathrm{~S}$ fully mechanised caving faces were associated with the graben structure. The activity of the graben fault in the mining process of the $2305 \mathrm{~S}$ working face was studied by means of numerical simulation in this study.

According to the geological conditions of this mine, the immediate roof of the coal seam was mainly composed of fine sandstone and medium sandstone and a sandstone composite tight roof of 18-40 m thickness within the $60 \mathrm{~m}$ range above the coal seam. At the seam floor, there were mainly mudstone, fine sandstone, and medium sandstone. The local thickness of the mudstone ranged from 1 to $5 \mathrm{~m}$, and the sandstone thickness was 5-20 m. Located at the north of the working face, the FD8 fault-a normal fault-was mainly to the north of the Sanlian Roadway, obliquely intersecting with the working face with an actual exposure throw of $10-15 \mathrm{~m}$, a dip angle of $70^{\circ}$, a dip direction of northwest, and a strike of northeast. The extended length of the fault on the working face was $720 \mathrm{~m}$. The fault throw presented a gradual growth trend from the north to south, which had a great impact on the mining of this working face. The FD6 fault, which was a normal fault, was located at the north of the 2404 S working face, the excavation of which was completed in 2019 with a throw of $0-10 \mathrm{~m}$, a dip angle of $70^{\circ}$, a dip direction of southeast, and a strike of northeast. The extended length of this fault on the 2304 S working face was $400 \mathrm{~m}$.

The "graben" composed of FD6 and FD8 fault groups in the New Dragon Coal Mine was taken as the main study object. A $3 \mathrm{D}$ numerical calculation model was established via FLAC3D for which the modeling and mesh generation were realised using ABAQUS software. The overall dimensions of the numerical model were $500 \mathrm{~m}$ (length) $* 500 \mathrm{~m}$ (width) $* 88 \mathrm{~m}$ (height), the roadway excavation dimensions were $200 \mathrm{~m}$ (length) $* 200 \mathrm{~m}$ (width) $* 3.6 \mathrm{~m}$ (height), and the dip angle, thickness, and throw of the fault were $70^{\circ}, 4 \mathrm{~m}$, and $10 \mathrm{~m}$, respectively. The thickness value of each stratum in the vertical direction of the model was, from top to down, $32 \mathrm{~m}$ (medium sandstone), $28 \mathrm{~m}$ (fine sandstone), $3.6 \mathrm{~m}$ (coal), $4.4 \mathrm{~m}$ 
(mudstone), and $20 \mathrm{~m}$ (medium-fine sandstone). The ABAQUS and FLAC3D overall models are shown in Figure 4, and the basic mechanical parameters of rocks are shown in Table 1. A total of 139,808 mesh elements were generated in the model, where the number of mesh elements in the roadway was 3,276.

A load was applied to the upper end face of the model, with its size equivalent to the dead weight of the overlying strata above the upper model boundary. The Mohr-Coulomb model was used with the boundary conditions as shown in Figure 5. The boundaries on the six planes of the model had fixed displacements, which constituted the model boundary conditions. Vertical constraints were applied to the upper and lower bottom boundaries of the model, and horizontal fixed constraints were applied to the periphery boundaries [24].

4.2. Stress State Analysis. The stress change of the surrounding rock is a dynamic process. After the roadway excavation, a complex ground stress state was formed. The surrounding rock was under a two-way or one-way stress state, destroying the original mechanical equilibrium state inside the rock mass and resulting in the damage under the action of concentrated stress [25]. The vertical stress field of the surrounding rock evolved as shown in Figure 6.

From Figure 6, during the roadway excavation under the form of the graben structure, small stress concentration zones appeared nearby the two walls of the roadway. Large stress reduction zones existed at two sides of the roof and floor, and the peak stress continuously increased. The range of the stress concentration expanded somehow, and the stress concentration coefficient at the upper and lower parts of the floor elevated from 1.67 at $0 \mathrm{~m}$ to 2.3 at $75 \mathrm{~m}$. As the excavation proceeded closely to the fault surface, the stress concentration zones at the two walls of the roadway reduced, and the stress reduction zone was located nearby the lower part of the floor.

As shown in Figures 7 and 8, during the roadway excavation, the shear stress concentration took place at the wall corner of the roadway. The concentration factor continuously increased with the increase in the distance from the fault, with its peak value firstly increasing and then decreasing. The peak value continued to rise in comparison with the concentration factor nearby the fault. Moreover, according to the reciprocal principle of shear stress, shear stress appeared in pairs, with the shear stresses on two adjacent planes being in the opposite directions. After the roadway became stable, $\tau_{x y}=16 \mathrm{MPa}$ and $\tau_{y z}=8.5 \mathrm{MPa}$.
4.3. Plastic Zone Analysis. The range of the plastic zone is an important factor influencing the stability of the surrounding rock. In Figure 9, none means elastic; shear- $n$ tension- $n$ shear- $p$ tension- $p$ represents the shear and tensile failure and shear and tensile yield; shear- $n$ shear- $p$ tension- $p$ denotes the shear failure or yield and tensile yield; tension- $p$ is the tensile yield; tension- $n$ shear- $p$ tension- $p$ expresses the tensile failure and shear and tensile yield; shear- $n$ tension- $n$ is the shear and tensile failure; and tension- $n$ tension- $p$ is the tensile failure or yield.

It can be observed from Figure 9 that the stress concentration zones were formed at the roof and floor of the roadway. The shear failure of the roadway floor at $0 \mathrm{~m}$ from the fault was serious, and the initial fracture zone of the roadway surrounding rock was mainly concentrated at the side of the floor. Nearby the floor was mainly tensile failure, the fracture zones above the roof increased, and the top plastic zone was mainly tension-shear-mixed failure zone.

In conclusion, when the working face advanced towards the graben fault under the effect of vertical stress at different distances, the stress concentration zones formed at two walls. Large stress reduction zones appeared at the roof and floor, and the influence generated by the fault on the peak stress was continuously mitigated with the increase in distance. As a result, the stress concentration zones continuously expanded, the peak stress was elevated, but the distribution law was basically unchanged. A shear stress concentration zone appeared at the wall corner of the roadway, and the rock masses at the roof and floor became prone to tensile failure [26]. The rock failure was mainly triggered by compressive and shear stresses. The shear slip failure of the rock mass induced by the shear stress concentration was the most common failure type, and the graben fault would experience the slip instability due to the vertical stress.

This paper based on the theoretical analysis of the graben fault instability mechanism to obtain the judgement basis of fault instability and the specific location of the maximum shear force on the roof. It is also known that the main reason for fault instability is that the shear stress of the graben roof element is greater than the shear strength of the fault. So, it is concluded that rocks' tangential dislocation is mainly caused by shear stress. Through numerical simulation, it is also found that the main cause of rocks' dislocation failure is shear stress concentration under vertical stress. The numerical simulation method can accurately verify the results of theoretical analysis, and the theoretical analysis also provides a basis for the reliability of the numerical simulation. 

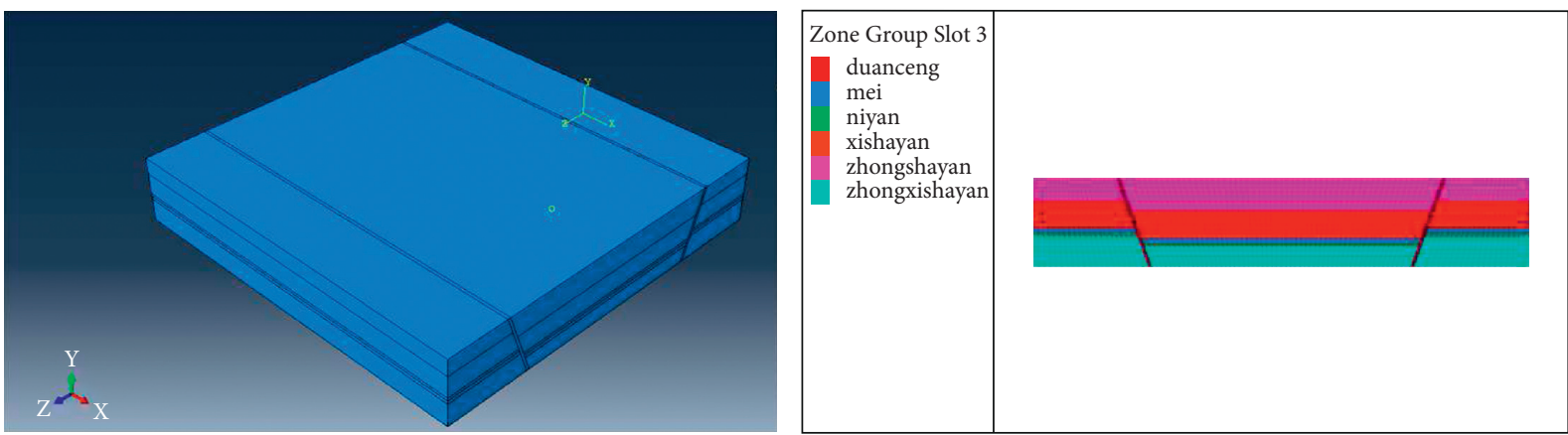

Figure 4: ABAQUS and FLAC3D overall models.

TABle 1: Mechanical parameters of rocks.

\begin{tabular}{|c|c|c|c|c|c|c|}
\hline Rock & $\begin{array}{c}\text { Density } \\
\left(\mathrm{kg} \cdot \mathrm{m}^{-3}\right)\end{array}$ & $\begin{array}{c}\text { Bulk modulus } \\
(\mathrm{GPa})\end{array}$ & $\begin{array}{l}\text { Shear modulus } \\
(\mathrm{GPa})\end{array}$ & $\begin{array}{c}\text { Internal frictional } \\
\text { angle }\left({ }^{\circ}\right)\end{array}$ & $\begin{array}{c}\text { Cohesion } \\
(\mathrm{MPa})\end{array}$ & Tensile strength $(\mathrm{MPa})$ \\
\hline Medium sandstone & 2450 & 3.83 & 2.41 & 41 & 3.26 & 36 \\
\hline Fine sandstone & 2600 & 3.45 & 2.00 & 40 & 3.80 & 1.80 \\
\hline Coal & 1400 & 3.00 & 1.00 & 28 & 1.60 & 0.90 \\
\hline Mudstone & 2300 & 4.45 & 1.60 & 39 & 3.30 & 1.75 \\
\hline $\begin{array}{l}\text { Medium fine-grained } \\
\text { sandstone }\end{array}$ & 2900 & 2.66 & 0.84 & 35 & 2.85 & 1.10 \\
\hline Fault rock & 1000 & 0.074 & 0.50 & 22 & 0 & 0 \\
\hline
\end{tabular}

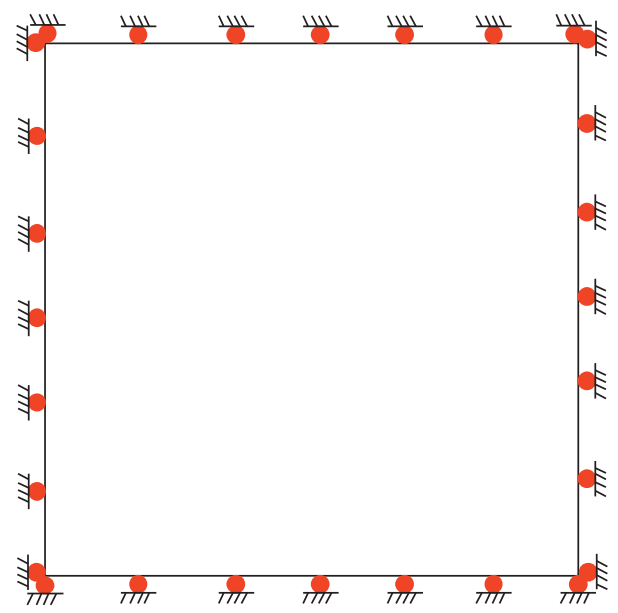

Figure 5: Boundary conditions.

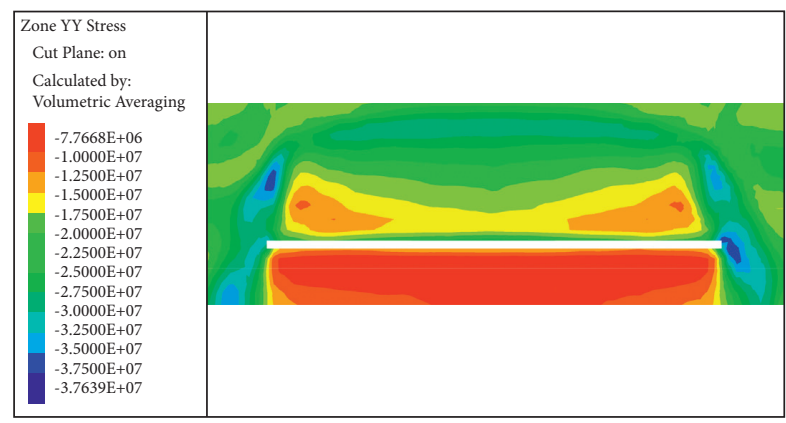

(a)

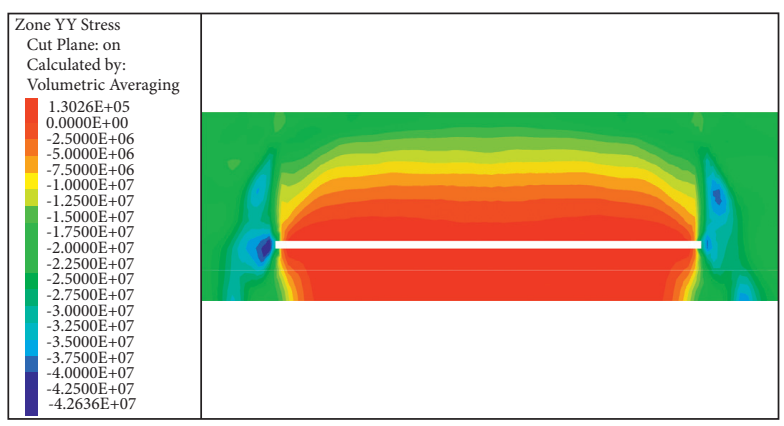

(b)

Figure 6: Continued. 


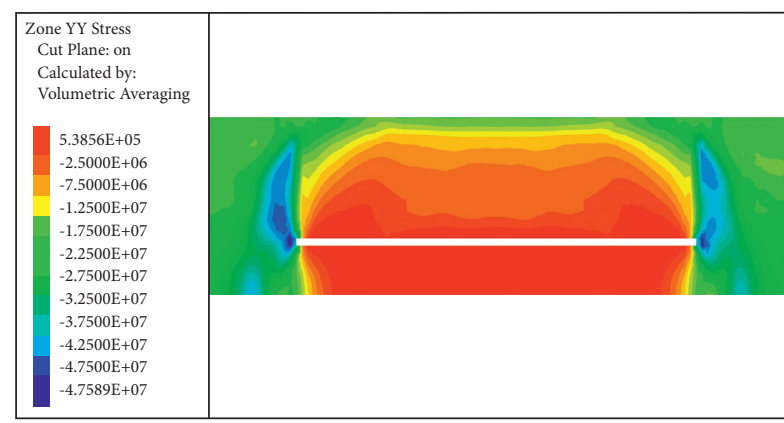

(c)

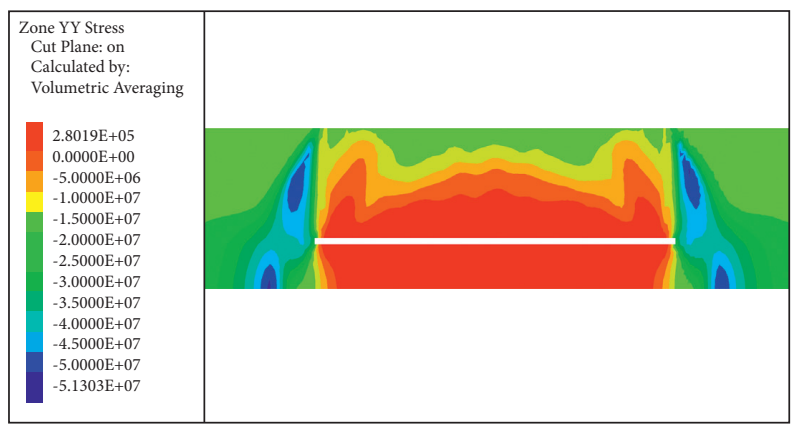

(e)

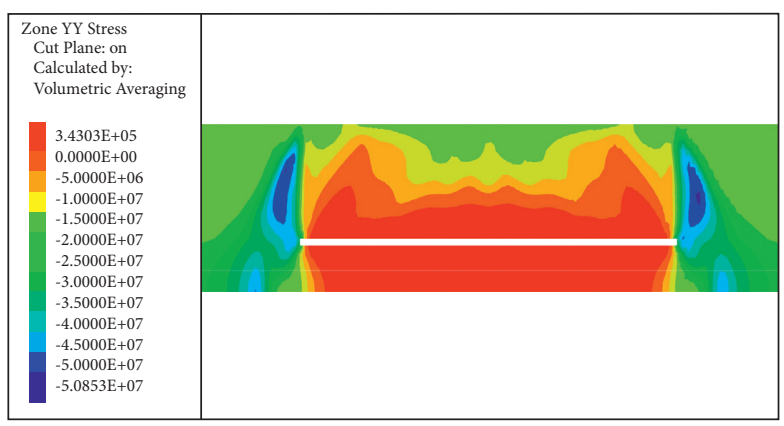

(d)

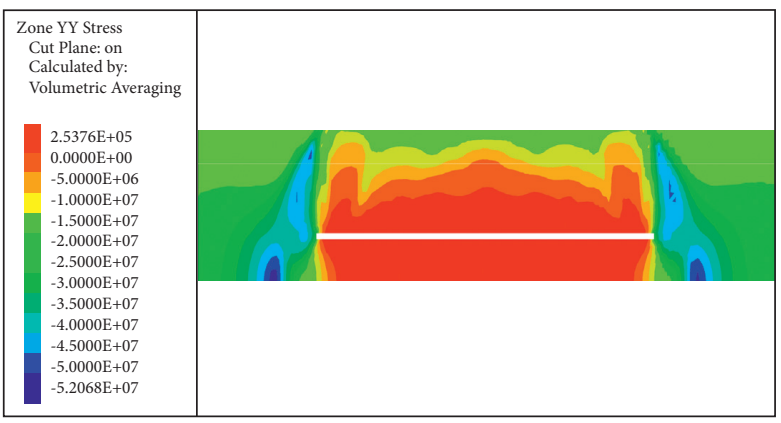

(f)

FIGURE 6: Vertical stress field of the surrounding rock. (a) $0 \mathrm{~m}$. (b) $15 \mathrm{~m}$. (c) $30 \mathrm{~m}$. (d) $45 \mathrm{~m}$. (e) $60 \mathrm{~m}$. (f) $75 \mathrm{~m}$.

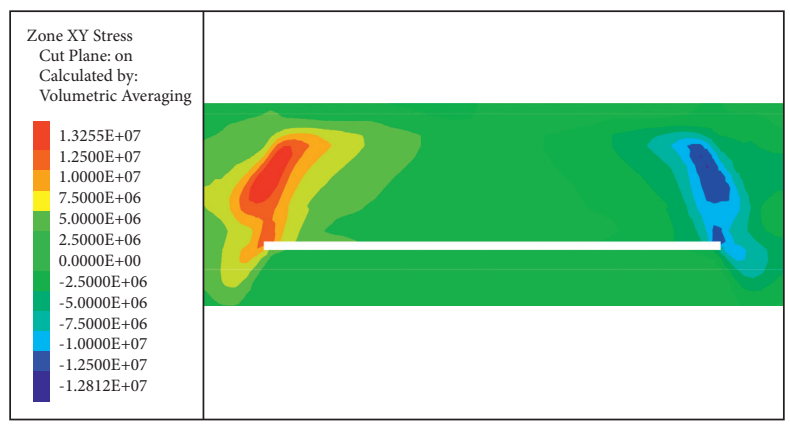

(a)

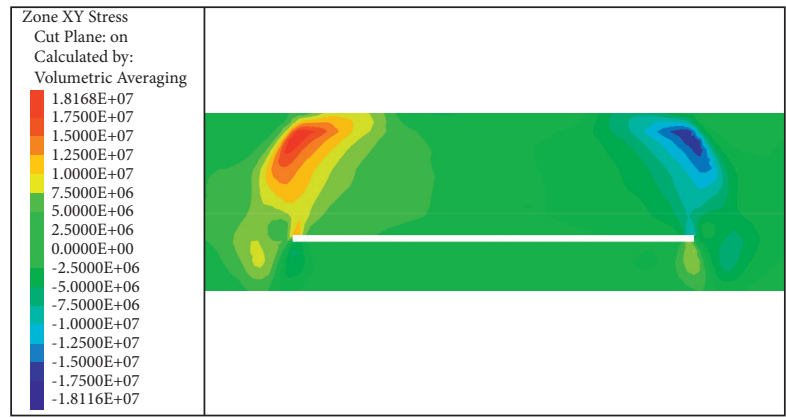

(c)

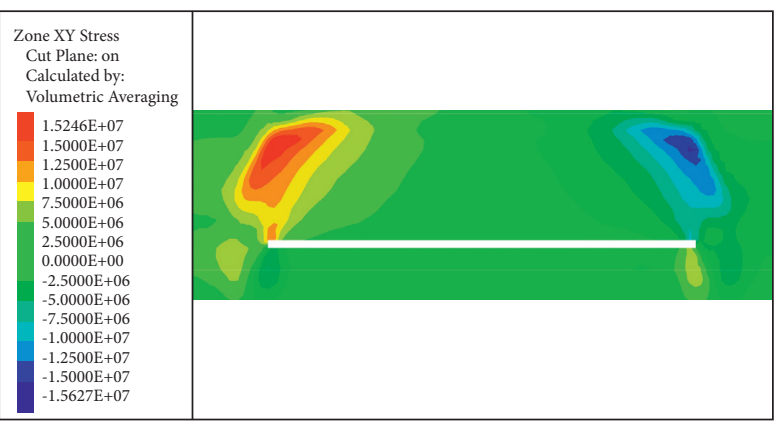

(b)

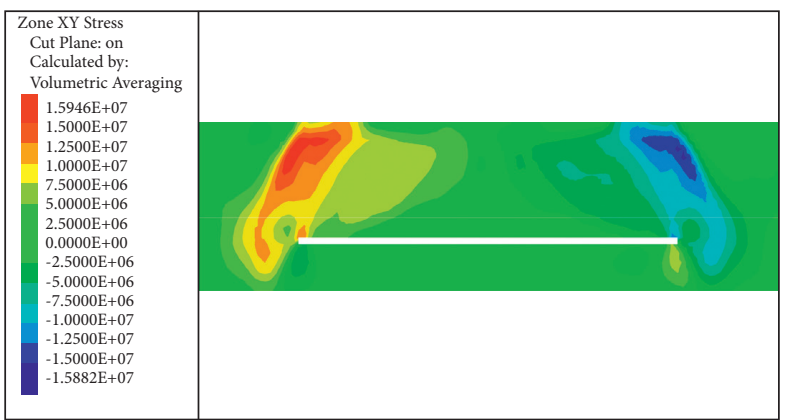

(d)

Figure 7: Continued. 


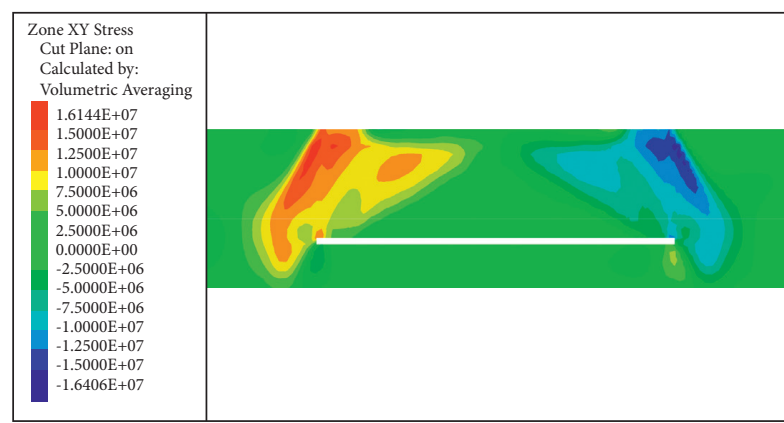

(e)

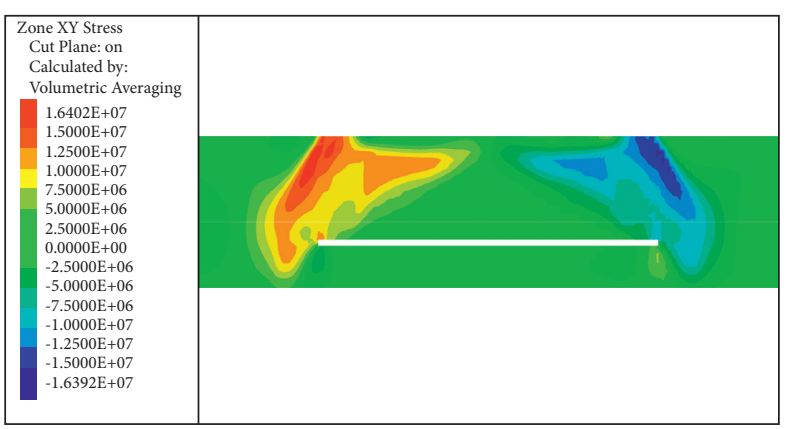

(f)

Figure 7: Shear stress in the $X-Y$ plane cloud image. (a) $0 \mathrm{~m}$. (b) $15 \mathrm{~m}$. (c) $30 \mathrm{~m}$. (d) $45 \mathrm{~m}$. (e) $60 \mathrm{~m}$. (f) $75 \mathrm{~m}$.

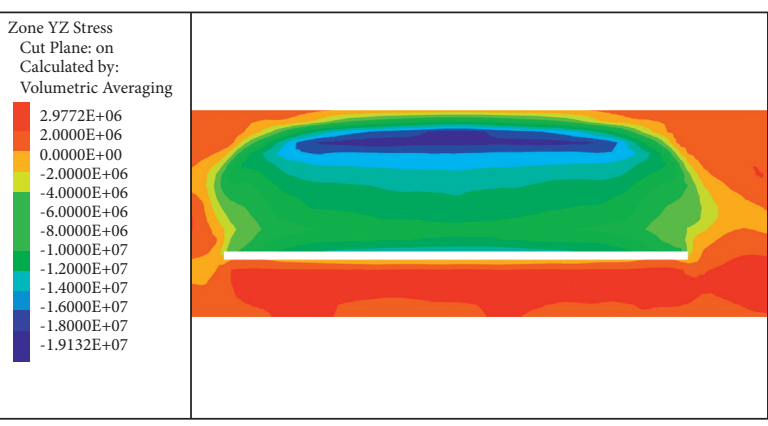

(a)

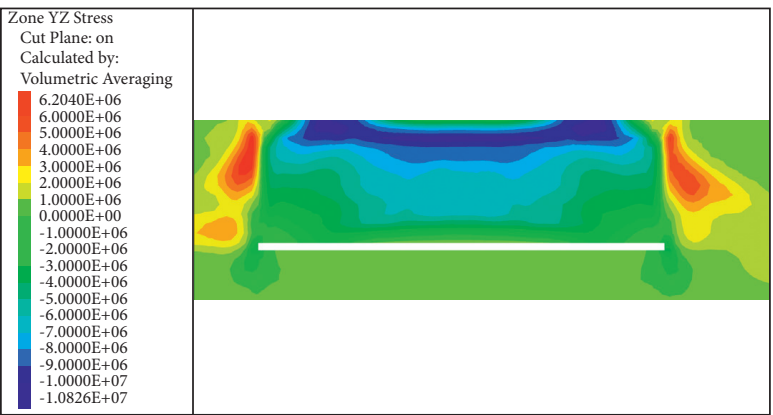

(c)

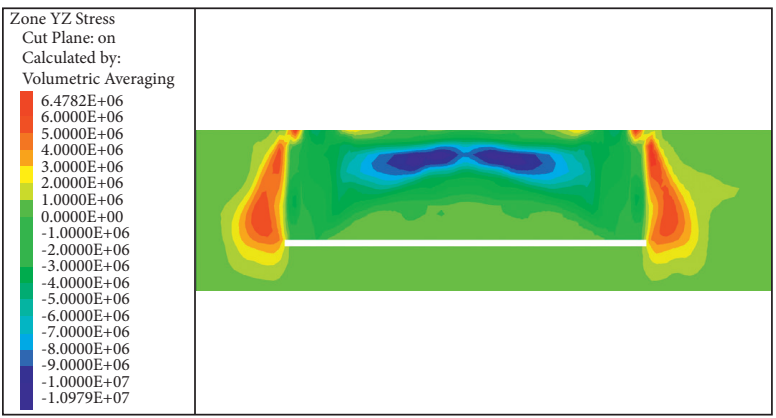

(e)

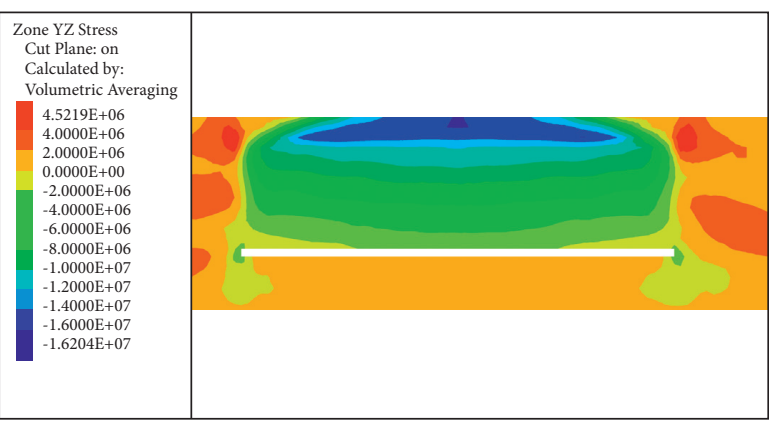

(b)

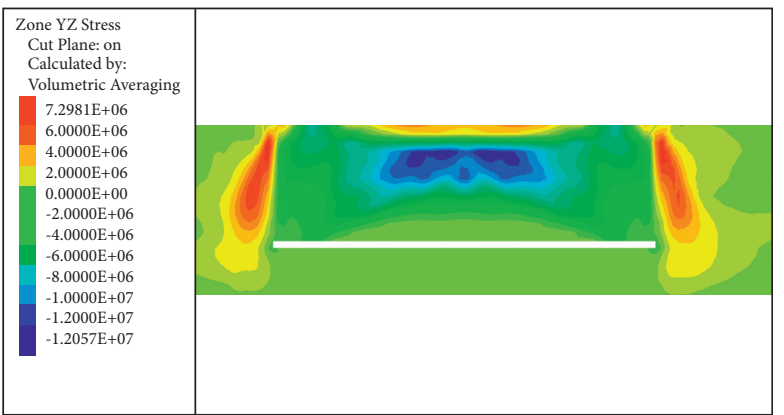

(d)

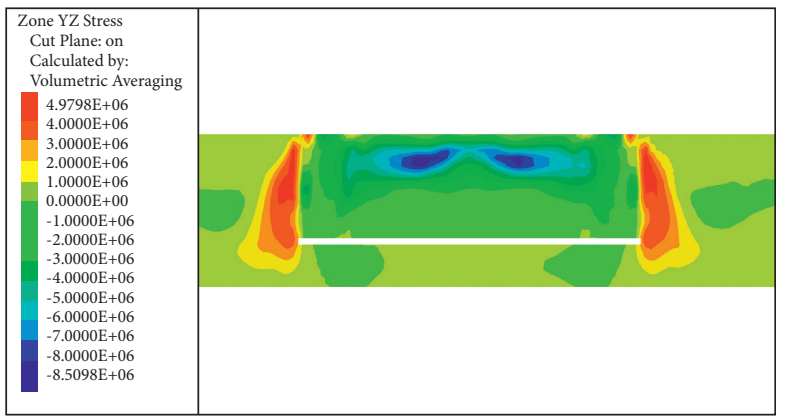

(f)

Figure 8: Shear stress in the $Y$ - $Z$ plane cloud image. (a) $0 \mathrm{~m}$. (b) $15 \mathrm{~m}$. (c) $30 \mathrm{~m}$. (d) $45 \mathrm{~m}$. (e) $60 \mathrm{~m}$. (f) $75 \mathrm{~m}$. 


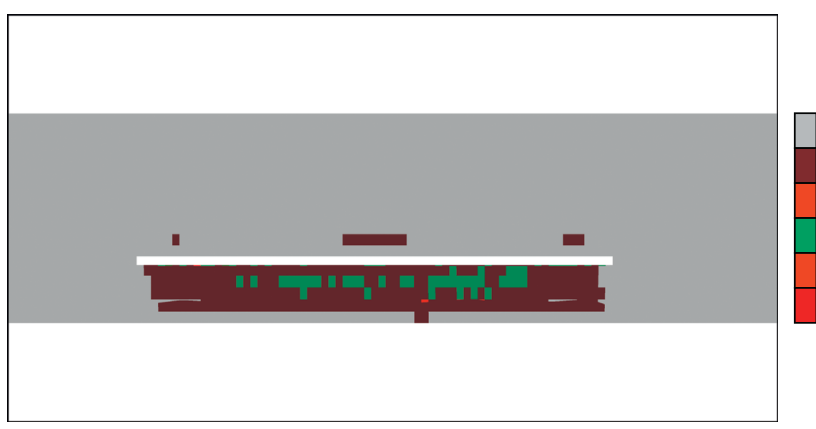

None

shear-n shear-p tension- $\mathrm{p}$

shear-p tension- $p$

tension- $n$ shear-p tension- $p$

tension- $n$ tension- $p$

tension-p

(a)

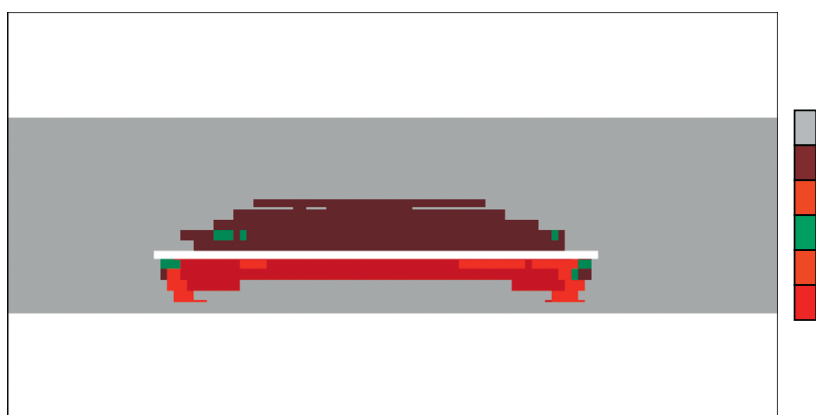

None

shear- $n$ shear-p tension- $p$

shear-p tension- $\mathrm{p}$

tension- $n$ shear-p tension- $p$

tension- $n$ tension- $p$

tension-p

(b)

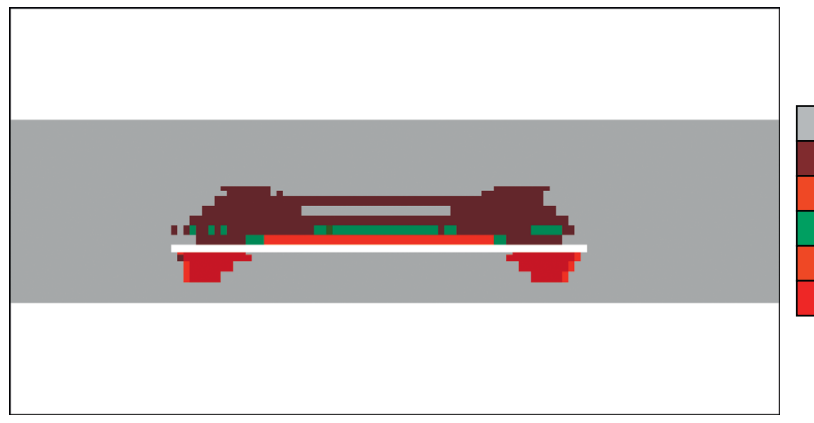

(c)

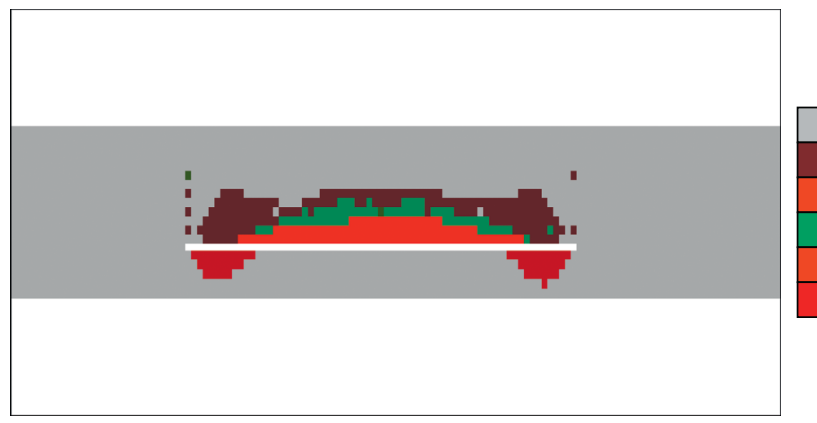

(d)

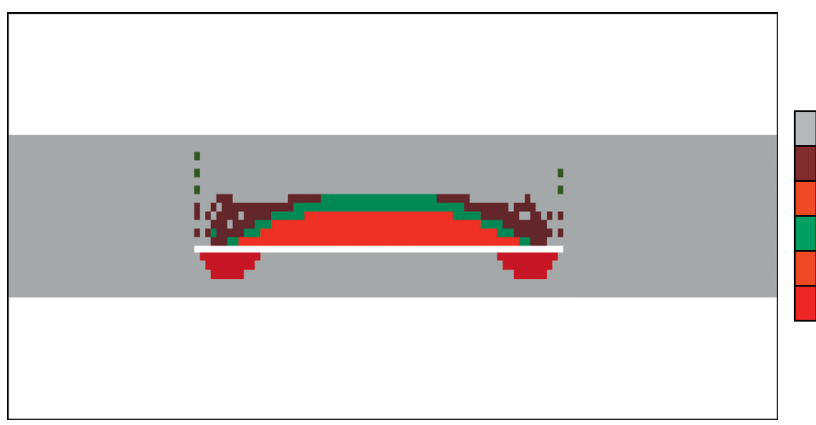

None

shear- $n$ shear-p tension- $p$

shear-p tension- $p$

tension- $n$ shear-p tension- $p$

tension- $n$ tension- $p$

tension-p 


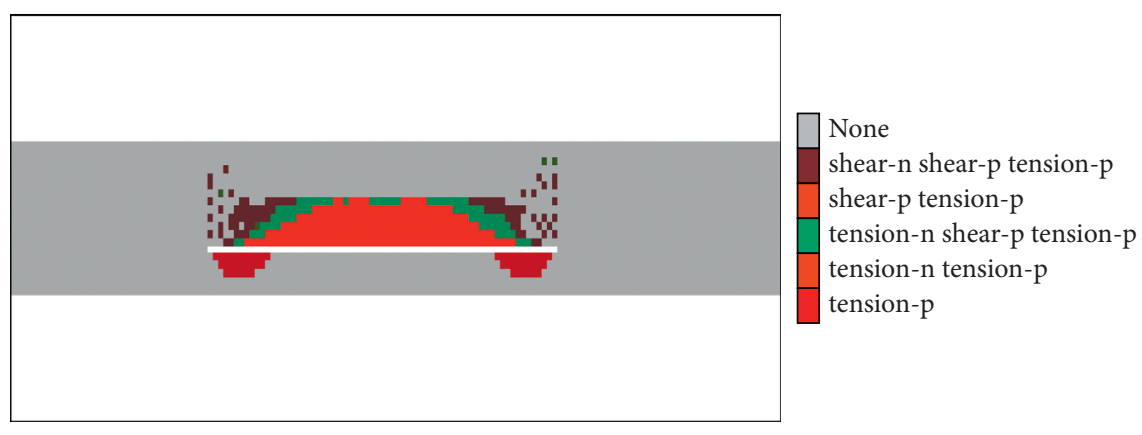

(f)

Figure 9: The plastic range. (a) $0 \mathrm{~m}$. (b) $15 \mathrm{~m}$. (c) $30 \mathrm{~m}$. (d) $45 \mathrm{~m}$. (e) $60 \mathrm{~m}$. (f) $75 \mathrm{~m}$.

\section{Conclusion}

Under the background of a rock burst accident in the New Dragon Mine, the evolution laws of roof stress in a graben fault structure during the mining process were studied, and the importance was attached to the reinforcement of vulnerable parts at fixed points under different states. On this basis, the change laws of the stress field and displacement nearby the graben fault were explored through a numerical simulation, and afterward, the instability mechanism and laws of rock strata nearby the graben fault were intuitively revealed. Concrete conclusions were drawn from this study as follows:

(1) Through theoretical derivation and analysis, as the goaf span is increased, the supporting effect of the coal seam on the roof transits from the elastic support into the plastic support until the damaged support. By analysing different support states, the concrete positions at which the roof and graben fault-type roof bear the maximum shear force are obtained in an effort to realise early warning of roof weighing and reinforcement at fixed points.

(2) According to the numerical simulation analysis, during the advancement process of the working face towards this graben fault structure, a shear stress concentration zone appears at the wall corner of the roadway, and rock mass at the roof is vulnerable to tensile failure. The failure of rock mass is mainly induced by the joint action of compressive stress and shear stress. The shear slip failure induced by the shear force concentration is the most common failure mode, and the vertical stress will give rise to the slip instability of the graben fault.

\section{Data Availability}

The raw/processed data required to reproduce these findings cannot be shared at this time as the data also form part of an ongoing study.

\section{Conflicts of Interest}

The authors declare no conflicts of interest.

\section{References}

[1] G. Zhu, L. Dou, H. Wang, H. Liu, and G. Dong, "Back analysis of rock burst risk and fault slip due to mining in the island panel along fault: a case study of island panel 3108 in Chaoyang coal mine," Journal of China Coal Society, vol. 45, pp. 533-541, 2020.

[2] C. Wei, C. Zhang, I. Canbulat, A. Cao, and L. Dou, "Evaluation of current coal burst control techniques and development of a coal burst management framework," Tunnelling and Underground Space Technology, vol. 81, pp. 129-143, 2018.

[3] M. Gao, Z. Song, H. Duan, H. Xin, and J. Tang, "Mechanical properties and control rockburst mechanism of coal and rock mass with bursting liability in deep mining," Shock and Vibration, vol. 2020, Article ID 8833863, 15 pages, 2020.

[4] G. Wang, S. Gong, L. Dou, W. Cai, X. Yuan, and C. Fan, "Rockburst mechanism and control in coal seam with both syncline and hard strata," Safety Science, vol. 115, pp. 320-328, 2019.

[5] Y. Pan, Z. Li, and M. Zhang, "Diutribution, type, mechanism and prevention of rockburst in China," Chinese Journal of Rock Mechanics and Engineering, vol. 11, 2003.

[6] J. Pan, Y. Ning, D. Mao, H. Lan, T. Du, and Y. Peng, "Theory of rockburst start-up during coal mining," Chinese Journal of Rock Mechanics and Engineering, vol. 31, pp. 586-596, 2012.

[7] H. Lan, Q. Qi, J. Pan, and Y. Peng, "Analysis on features as well as prevention and control technology of mine strata pressure bumping in China," Coal Science and Technology, vol. 39, pp. 11-15, 2011.

[8] M. He, F. Ren, and D. Liu, "Rockburst mechanism research and its control," International Journal of Mining Science and Technology, vol. 28, no. 5, pp. 829-837, 2018.

[9] W. D. Ortlepp and T. R. Stacey, "Rockburst mechanisms in tunnels and shafts," Tunnelling and Underground Space Technology, vol. 9, no. 1, pp. 59-65, 1994.

[10] J. He, Study of Structural Control Mechanism on Groundwater in the North Mining Area of Huainan Coal Field, AnHui University of Science and Technology, Huainan, China, 2015.

[11] Y. Pan, L. Wang, M. Zhang, and B. Xu, "The theoretical and testing study of fault rockburst," Chinese Journal of Rock Mechanics and Engineering, vol. 17, pp. 642-649, 1998.

[12] W. Yu and K. Li, "Deformation Mechanism and Control Technology of Surrounding Rock in the Deep-Buried LargeSpan Chamber," Geofluids, vol. 2020, Article ID 8881319, 22 pages, 2020.

[13] W. Yu, K. Li, Z. Liu, B. An, P. Wang, and H. Wu, "Mechanical characteristics and deformation control of surrounding rock 
in weakly cemented siltstone," Environmental Earth Sciences, vol. 80, pp. 1-15, 2021.

[14] M. M. Nordiana, M. Syukri, R. Saad, M. Abubakar, and N. A. Kamaruddin, "The identification of fault zones in Krueng Raya, Aceh Besar (Indonesia) using magnetic method," Electronic Journal of Geotechnical Engineering, vol. 19, pp. 1-9, 2014.

[15] H. Wu, D. Ma, A. Spearing, and G. Zhao, "Fracture response and mechanisms of brittle rock with different numbers of openings under uniaxial loading," Geomechanics and Engineering, vol. 25, pp. 481-493, 2021.

[16] D. Ma, H. Duan, J. Liu, X. Li, and Z. Zhou, "The role of gangue on the mitigation of mining-induced hazards and environmental pollution: an experimental investigation," The Science of the Total Environment, vol. 664, pp. 436-448, 2019.

[17] Y. Zhao, Y. Pan, and H. Yu, "Analysis of Fault Rockburst Based on Shear Beam Model for Interface Failure," Rock and Soil Mechanics, vol. 28, pp. 1571-1576, 2007.

[18] K. Mongi, "Study of the elastic shocks caused by the fracture of heterogeneous materials and its relation to earthquakes phenomena," Bulletin of the Earthquake Research Institute, vol. 40, pp. 125-173, 1962.

[19] Z. Mróz and P. Nawrocki, "Deformation and stability of an elasto-plastic softening pillar," Rock Mechanics and Rock Engineering, vol. 22, no. 2, pp. 69-108, 1989.

[20] D. Ma, J. Zhang, H. Duan et al., "Reutilization of gangue wastes in underground backfilling mining: overburden aquifer protection," Chemosphere, vol. 264, Article ID 128400, 2021.

[21] D. Ma, S. Kong, Z. Li, Q. Zhang, Z. Wang, and Z. Zhou, "Effect of wetting-drying cycle on hydraulic and mechanical properties of cemented paste backfill of the recycled solid wastes," Chemosphere, vol. 282, Article ID 131163, 2021.

[22] C. Su, Z. Xiong, X. Zhai, and M. Gu, "Analysis of deformation and strength characteristics of coal samples under the triaxial cyclic loading and unloading stress path," Journal of Mining \& Safety Engineering, vol. 31, pp. 456-461, 2014.

[23] X. Zhang, "Forecast of basic roof weighting based on elastic shearing beam model," Journal of Mining And Strata Control Engineering, vol. 14, pp. 83-84+19, 2009.

[24] Y. Q. Lv, H. F. Liu, and J. J. Yang, Study of Failure Mechanism of Anti-dip Rocks Materials Slope under Mining Subsidence, Advanced Materials Research, pp. 1097-1101, Trans Tech Publ, Zurich, Switzerland, 2011.

[25] A. Manouchehrian and M. Cai, "Numerical modeling of rockburst near fault zones in deep tunnels," Tunnelling and Underground Space Technology, vol. 80, pp. 164-180, 2018.

[26] J. Ryder, "Excess shear stress in the assessment of geologically hazardous situations," Journal of the South African Institute of Mining and Metallurgy, vol. 88, pp. 27-39, 1988. 